\title{
Exploring a Women-Only Training Program for Coach Developers
}

\author{
Erin Kraft and Diane M. Culver \\ Cari Din \\ University of Ottawa \\ University of Calgary
}

\begin{abstract}
The following practice paper introduces an innovative women-only training program for coach developers in a Canadian provincial sport organization. The dearth of women in coaching and sport leadership positions informs the program as a whole and the participant perspectives on what is working, in practice, for them specifically in a way that could support future sport leaders interested in increasing gender equity in their sport organizations and leadership skills in their female leaders. The aims of the coach developer program are two-fold: to promote women in leadership and to create a social learning space for women to connect and support each other in their leadership development. The purpose of this practice paper is to discuss the supports that have enabled the facilitation of this program and to explore the value of a women-only training program. Two women (out of a total of 10) participating in the program and two leads facilitating the program were interviewed for their perspectives. The lessons learned touch on the types of value that were created (immediate, potential, and applied) and the specific supports (micro, meso, and macro) that enabled the facilitation of the program. Finally, the authors discuss additional considerations (e.g., consistent buy-in from the organization is needed) with practical insights in the hopes of inspiring other sport organizations to implement similar initiatives for promoting women in leadership and coaching in sport.
\end{abstract}

Keywords: gender, leadership, social learning

There is a considerable gender imbalance in leadership positions across several fields including healthcare, academia, and business (Kalaitzi, Czabanowska, Fowler-Davis, \& Brand, 2017). In sport specifically, we are seeing the number of women in leadership decreasing (Demers, Thibault, Brière, \& Culver, 2019). There has been a notable shortage in female head coaches in the United States (Machida-Kosuaga, Schaubroek, Gould, Ewing, \& Feltz, 2017) and a general underrepresentation of women in sport leadership positions on a global scale (LaVoi, 2016). Moreover, the number of women securing board membership positions on Canadian National Sport Organizations (NSOs) is consistently less than 30\% (CAAWS, 2018). To explore this trend, in 2012, LaVoi and Dutove conducted a review of literature, using Bronfenbrenner's Ecological Systems Theory (1977, 1979) to synthesize the barriers experienced by women seeking and retaining coaching positions at a variety of levels in sport. The barriers LaVoi and Dutove (2012) identified included a perceived lack of confidence and competence, feeling undervalued, and a lack of collegial support. In another review, Carson, McCormack, and Walsh (2018) recognized additional barriers for women coaches such as a lack of women in leadership positions to act as supports, the pressures of working in a male-dominated environment, and job insecurity. When women did secure coaching positions, they experienced a host of additional barriers as they attempted to take on new leadership roles. These barriers included perceived gender discrimination, which impacted the coaches' intentions to advance into leadership positions, and fewer opportunities to participate in developmental challenges than their male counterparts (Machida-Kosuaga et al., 2017). In addition, Burton (2015) found

Kraft and Culver are with the School of Human Kinetics, University of Ottawa, Ottawa, Ontario, Canada. Din is with the Faculty of Kinesiology, University of Calgary, Calgary, Alberta, Canada. Kraft (ekraf090@uottawa.ca) is corresponding author. males were predominantly holding the gatekeeper roles for delegating new leadership positions and tended to be favorable towards hiring men. In light of more than 20 years of research examining the gender bias against women in coaching (e.g., Knoppers, 1992), it is concerning that this gender imbalance persists today.

In an effort to confront the barriers noted above and increase gender equity and leadership diversity in sport organizations, an initiative in a Canadian province was developed: The Alberta Women in Sport Leadership Impact Program (AWiSL). This federally funded project (from the Department of Women and Gender Equality) was initiated in the province of Alberta by recruiting 12 sport leaders to plan, implement, and evaluate distinct programs in their sport organizations to increase gender equity and leadership development. For the purpose of this practice paper, we focus on one of these 12 sport organizations to take a closer look at their initiative titled Women in Sport Leadership (WiSL). Readers are referred to Culver, Kraft, Din, and Cayer (2019) for more information on the larger AWiSL program. In this practice paper, we describe the systems which supported this initiative and the value of using, in this practice case, a women-only training program (WOTP; the model used for the WiSL) from the perspectives of two women in the program and two lead facilitators. Our purpose is to share the perspectives and experiences to provide readers with the opportunity to envision a vicarious experience and develop a naturalistic generalization (Creswell, 2013). This type of generalization can be defined as:

... a process where readers gain insight by reflecting on the details and descriptions presented ... as readers recognize similarities in case study details and find descriptions that resonate with their own experiences; they consider whether their situations are similar enough to warrant generalizations (Melrose, 2009, p. 599).

Thus, readers wishing to create a training program that enables learning and leadership development opportunities for women in 
sport organizations may reflect on this practice paper and consider whether it fits into their own contexts. The next section discusses other WOTP to situate the current program.

\section{Women-Only Training Programs}

Kane (2016) argued that the situation for women in leadership has not changed even though "sophisticated on-the-ground initiatives for change have been undertaken, the intended outcomes have not materialized, at least in any significant way" (p. 36). Kane (2016) explained that some of the persistent barriers for women coaches include the lack of institutional support to access professional training and development opportunities, and the lack of women for networking and mentoring. Thus, implementing a new initiative with the hopes of breaking this cycle and supporting women in sport leadership is warranted.

Organizations across many fields have initiated continuing education programs to empower women and create opportunities for leadership development. One such example of an empowering initiative for women is gender-specific programs or WOTP seen in business (Bullough, De Luque, Abdelzaher, \& Heim, 2015), academics (Gronowski \& Burnham, 2018), as well as various workplaces (Chuang, 2019) including sport (e.g., Allen \& Reid, 2019; Belding \& Dodge, 2016). According to Chuang (2019) "due to gender difference in learning, communication, emotional intelligence, motivation, leadership, problem-solving (. . . and the list goes on), WOTP can provide a supportive and comfortable learning environment to enhance women's confidence, skills, continuous development and readiness for future work" (p. 10). Chuang (2019) continued by explaining "literature indicates men tend to dominate learning settings and working environments while women are shyer from dominating a group with mixed genders" (p. 8). Considering the "old boys club" in sport coaching is deemed a contributor to the decrease in female coaches (Lumpkin, Favor, \& McPherson, 2013), creating spaces for a WOTP could mitigate this barrier. As such, the WOTP was an appropriate approach to apply to the WiSL initiative. The aim of this practice paper is to provide a snapshot of the program from the perspectives of two coach developers (CDs), as well as the two leads who promoted this initiative in the organization. This snapshot illuminates the potential of executing a WOTP for CDs when the appropriate supports are in place and will hopefully provide context and examples for other wishing to implement a similar initiative.

\section{Description of WiSL}

The WiSL is a two-year WOTP that sets up 10 women to become certified CDs with the skills to promote and facilitate learning for coaches. The women have cultivated a social learning space as this approach underpins the WiSL program and is the same one used by the greater AWiSL program. Social learning spaces are facilitated when groups of practitioners who care to make a difference in their context come together, share problems, and co-create solutions and, ultimately, improve their practice (Wenger, 2011). In addition, an Ecological Systems approach accounts for the various systems which have supported the implementation of this program. The next section provides an overview of these two guiding theories for future iterations of a similar program. Following, we present information about WiSL participants, examples of activities, lessons learned, and additional considerations.

\section{Conceptual Framework}

The WiSL accounted for both the systems that enabled the CD's learning (how) and the perceived value of participating in a social learning initiative (what) using two theories. Bronfenbrenner's (1977, 1979) Ecological Systems Theory (EST) accounts for "how" systems have enabled the learning in this community, whereas Wenger, Trayner, and de Laat's (2011) Value Creation Framework (VCF) reveals "what" value has been created for these women in this social learning space. The EST has previously been used to identify barriers for women in leadership across sport systems (Burton, 2015; LaVoi \& Dutove, 2012) and the VCF has been used as a tool to assess value, particularly in the context of social learning spaces for women coaches in sport (Bertram, Culver, \& Gilbert, 2017; Culver et al., 2019). Below are descriptions of ecological systems and value creation cycles along with examples from the WiSL.

Ecological Systems. Drawing from Bronfenbrenner (1979), the three ecological systems include microsystems (micro), mesosystems (meso), and macrosystems (macro); all three systems play a role in supporting the program. A microsystem is a series of interpersonal relations experienced by an individual. For example, the relationships cultivated between the CDs, the leads, and others involved in this initiative enabled the CDs to discuss and learn from others. A mesosystem comprises the interrelations between several settings experienced by an individual. For example, the organizational supports and opportunities that were deliberately put into place allowed the $\mathrm{CD}$ to have the space and capacity to learn. A macrosystem includes the cultures and ideologies as a whole that exist around the individual. For example, the cultural influences and practices which enabled and prevented learning for the CD's throughout this initiative.

Value Creation Cycles. For the purposes of this paper, we focus on the first three value creation cycles according the Wenger et al. (2011). These cycles consist of Immediate, Potential, and Applied value. Immediate value is an activity or an interaction that inherently creates value. For example, CD 1 participates in a Mentorship Monday meeting. Potential value is an activity or interaction that leads to an idea that has potential to become valuable at a later time. For example, CD 2 participates in a Mentorship Monday meeting and explains that she has a tool that she uses to assist with her confidence when presenting. CD 2 shares this tool with CD 1 . Although CD 1 has not yet used the tool, there is potential for it to become valuable to her in the future. Applied value occurs when the potential idea is applied into a new context. For example, CD 1 delivers her first training (which requires presenting) and she uses the confidence tool she received from CD 2.

\section{Participants}

To gain insight into the WiSL, two of the women participating in the CD program (CD 1 and CD 2) and two leads (Lead 1 and Lead 2) facilitating the program shared their perspectives. Although the accounts of these two women do not capture the experiences of all 10 women in the program, we feel their diverse coaching experiences and locations provide important insight into the program and create a naturalistic generalization for readers. For example, CD 1 had been coaching for 12 years with a variety of age groups and levels and works in the education system. CD 2 had also been coaching on and off for the past 12 years (mostly coaching her children's teams) but became more deeply involved in coaching in the past four years and works as a health professional. 
For the program leads, we already had a relationship with Lead 1 through the AWiSL and she suggested that in addition to her perceptions of the program, Lead 2 (who is male) should share his perspectives as his experience may have been different from hers and she recognized the influence of his support throughout the program. It is important to acknowledge that although the program was specifically developed for women participants (to create a leadership development opportunity), male leads were welcomed to facilitate the program.

\section{Activities}

This initiative offered the CDs a number of training opportunities, hands-on activities, and social learning engagements. This section describes several activities from the first year of the program. In terms of training, the women participated in a weekend-long training where they were introduced to the $\mathrm{CD}$ role. This consisted of a training program which focused on developing learning facilitator skills. In addition, they attended another weekend course to gain insight into the competencies expected of them to eventually achieve their $\mathrm{C}$ license for coaching their sport. As for handson activities, the CDs were given the opportunity to co-deliver a workshop with an experienced $\mathrm{CD}$, to gain practical experience. This was followed by an opportunity to work alongside an experienced coach evaluator to gain an understanding of the expectations of evaluators during a formal coach evaluation. An example of a social learning engagement that took place, was the monthly Mentorship Monday meetings, where the CDs would meet with an expert or experienced $\mathrm{CD}$ and exchange experiences, co-create knowledge, and foster learning as a group. These interactions extended to an online platform (WhatsApp) where the women exchanged knowledge (i.e., articles) to help each other during periods where they were not meeting. Finally, the women participated in and presented at a Women in Sport Conference. This enabled them to listen and to participate in lectures from a variety of women in leadership roles (in sport and other fields) and provided them with an opportunity to work with an expert and develop their presentation skills. At the end of the first year, the CDs completed a formal reflection on the first year of the program and assisted with setting up actions for the second year.

\section{Lessons Learned}

\section{Supports to Facilitate a WOTP for CDs}

This section explores, from the perspectives of the two CDs and the two leads, the various systems (micro, meso, and macro) that, for the most part, supported the women's learning and development in the $\mathrm{CD}$ program. It is our hope that the direct quotes taken from the participants will inspire others to learn from their experiences and implement their own WOTP for leadership development. It is also important to note that the CD's and lead's experiences are not isolated to specific levels in the EST model as "all levels are not mutually exclusive and intersect in multiple and dynamic ways" (LaVoi \& Dutove, 2012, p. 20).

Micro Level: Creating Spaces for Connections (Social Learning). Identifying the specific micro-level supports is important in terms of developing leadership opportunities for women in sport, as there is often a focus on the barriers women face in securing and retaining leadership positions in sport (LaVoi \& Duvote, 2012). The strong sense of connection experienced by the women throughout the program played an important role in building a supportive network for their development: "To me a big part of it is the connections that I've made with some of the other participants in the group. So just having different people to bounce different ideas off of when you're maybe struggling with something. It's given me other options to look to for help" (CD 2). The WiSL provided coaches with training to become $\mathrm{CDs}$ and promoted a social learning experience where the women engaged in on-going interactions (both online and in-person), which was particularly important given the geographical distance between them: "We don't want it to end because we don't want to lose our touch with each other, because everyone is from all over the [province]" (CD 1). The participants are a geographically dispersed group of women, coaching and leading at a variety of levels and living in communities in many instances a four-hour drive away from other participants in this social learning space. Despite challenges to physical proximity, the participants in this program used digital platforms to connect and develop relationships.

In addition to making connections with other CDs, the participants appreciated the opportunity to meet with other women in leadership positions. Cragg, Costas-Bradstreet, Arkell, and Lofstrom (2016) explained that there is a lack of women in leadership positions across Canadian sports. Thus, woman coaches wishing to advance in their careers do not have the necessary role models and women in supportive roles to enable their development. The CDs had a variety of opportunities to interact with women in leadership roles at the Women in Sport conference (both in sport and other fields) and were paired with an expert who could support them in developing their leadership capacities, such as their presentation skills:

[She] came and helped us with our presentations [at the conference] then she gave us feedback. So, things we did well, things that we could look to improve on and then general comments which is also so nice. I know as an [educator] I love hearing feedback because that's how I grow and so it was nice to have someone be there to help guide us in our presentation, and then when we actually did our presentation give us feedback on it. So that whole experience was just cool. (CD 1)

Meso Level: Using Organizational Leverage to Support Women in Leadership. Women-only programs and events are important for maintaining women's continued participation in sport (Newland, 2019). This practice paper provides insight into a WOTP where the organization took pride in supporting women in their development. According to Burton (2019), "sport organizations led by those who value gender equity and foster a diverse organizational culture had more positive organizational outcomes for women and men" (p. 261). In this specific case, Lead 2 intentionally sponsored and facilitated growth opportunities for Lead 1 and the CDs:

Like I did with [Lead 1], what I've done with other female coaches ... [Lead 1] is an outstanding leader, she just needs to be given the opportunity to lead and so we talked about it, she reluctantly accepted the opportunity to take on more leadership. Early on I supported her a bit more and then after that I made myself difficult to get a hold of at times and then other times not so difficult because she figured it out. (Lead 2)

In turn, Lead 1 became more assertive and confident and even advocated for the $\mathrm{CD}$ program to push forward during a period when the program was not being prioritized: 
It's made me realize that, yes, there are certain things that I can push forward with, move forward with and it's okay. And I feel like the group, the coach developers, appreciated that and were feeling definitely like things were stagnating a little bit so I think they felt like, 'okay now we're, you know, we're getting some progress on here'. (Lead 1)

In sport organizations, women have often been denied access to resources and opportunities (Aicher \& Sagas, 2009). Significantly, in this case, we see the opposite. Lead 2 declared his sponsorship role and continued to leverage his access and support to the CDs and Lead 1 after his position changed from a local to distal level:

So, one of the coolest parts about all of this is that my new role is ensuring that we have really competent coach developers across the country getting opportunities to get identified, trained, mentored, evaluated, and certified. So, the 10 women that participated in this program were all participating in a coach developer program and so I will be able to help encourage [sport organizations] to ensure that these women are getting opportunities. So again, I'm in a sponsorship sort of role due to the job that I'll be doing, it was just one of the reasons why I took on the job because now I can have a similar sort of influence across the country, not just in the one province. (Lead 2)

The program leads also ensured the program supported participants' connections beyond the CD group. Wells and Hancock (2017) explained that networking is essential in sport, specifically for women's advancement in sport organizations. The leads facilitating this program picked up on these networking needs and offered the CDs mentorship and networking opportunities (e.g., at the Women in Sport conference) to support them in making these crucial connections.

Macro Level: Remaining Aware of the Androcentric Culture and Having a Strong Male Ally. The gendered communication that prevails across sport is so dominant that at times it is challenging to recognize. McGinnis, Chun, and McQuillian (2003) illuminated this point in the titles of tournaments; "the" championship is used for men, contrasted by the women's championship. This was mirrored by CD 1 as she spoke about her newfound awareness of the term "man on" when speaking to groups of women or girls: "I guess this would have been the biggest learning curve and still is because I still say 'you guys' and I don't mean to" (CD 1). This deep-rooted, androcentric culture was experienced by the CDs during their training. Although the WiSL provided the CDs with the tools to break through the glass ceiling that so often blocks women in sport leadership (Walker, Schaeperkoetter, \& Darvin, 2017), these women still faced push-back from male participants in the courses they were facilitating. Specifically, CD 2 from a rural community suggested that her presence in a leadership role will be an on-going challenge and opportunity for both herself and the androcentric sport community. She described a situation where she was challenged by a male counterpart:

It was just a couple of weekends ago, one of the guys at our table, kind of a young guy, really challenged me on like 'just get up there and lead something'. And I actually really, he just got my back up because it was like he challenged me in front of everybody and it didn't feel like a supportive thing, it just felt actually super intimidating. And yeah it was actually super uncomfortable. (CD 2)

Thus, it is important that the topic of sport being androcentric is included in CD programs to prepare women and men for navigating these challenges.
According to Auster and Prasad (2016), those who are in power determine what leadership looks like. And considering gender-based discrimination is so deeply embedded into coaching, some men cannot even conceive of having women in certain coaching positions (Walker \& Sartore-Baldwin, 2013). Lead 2 became aware that women were not being given opportunities to take on leadership roles and chose to challenge that culture:

I learned during the first weekend that there's not enough instances of sponsorship for women where there are individuals that have the capacity to open doors, that are prepared to open the doors and get out of the way. And so, I'm a believer in equality of opportunity and if we don't create and ensure that there's sufficient opportunities for women to get similar types of training, to get similar types of opportunities as men might get, and to get the, you know, the necessary supports to help them along that pathway, we don't have any hope of having an increase in leaders who are women, in my opinion. (Lead 2)

He admits that there are not enough people with his credibility, power, and perspective on this issue of opening doors for women, but the WiSL is an example of the potential impact of taking an active and consistent stance supporting and empowering women in sport. Moreover, Lead 2 participated in the on-going dialogue surfacing prominent ideologies, such as the double bind for women in organizations:

Just this last Monday we got into the juicy topic of the double bind that female leaders have when it comes to, you know, if they're a strong leader often they're judged in a negative sort of way. If they're not a strong leader then they're judged in another negative sort of way. So, you can't win. (Lead 2)

Shaw and Hoeber (2003) previously described the double bind in sport where women who are assertive are considered too aggressive, while men using the same directness are seen as leaders. Lead 2's role in this program may broaden his understanding of gender inequality and inform his modifications of coach education programs in his new positions. Thus, including male leads in this type of program may be beneficial for the CDs and beyond.

\section{Value Created for Women CDs When Social Learning Supports are in Place}

The following section explores the value of social learning experienced by the CDs through their participation in the WiSL. Considering the WiSL program is still in its beginning stages, it is plausible that value creation will continue and extend as the CDs have time to implement their learning and impact the sport contexts in which they lead.

Immediate Value. The CDs were constantly inspired just by being in contact with other women in the same position: "When we do get together, we get to feed off of each other and learn from each other" (CD 1). These connections have also been important for the CDs in terms of problem solving and accessing resources beyond the scope of the project:

You just have more resources to draw from which is helpful right? So, whether that's 'okay you know I'm really struggling with this in my coaching', I can throw that out to a few other people and get their input and what they think might work. (CD 2) 
Potential Value. As mentioned above, the CDs had the opportunity to engage with women leaders and have access to meaningful developmental opportunities. This instilled a desire to take on other opportunities so that they could pay it forward and act as leaders to other women coaches in the future:

When we got to present at the Women in Sport conference for [the province], it just made me hungrier to want to get all of my things that I need so I can be a [certified CD] so I can help develop coaches. (CD 1)

The connections developed between the CDs also enabled them to consider other perspectives with the potential to refine their own coaching: "Different people, different perspectives. They look at things differently and it gives you other ideas" (CD 2).

Applied Value. In addition to learning new skills, the CDs described an improved sense of confidence: "I think the program helped a lot ... maybe it gave me more confidence to keep pushing through things that maybe normally I would have given up on" (CD 2). This led to CD 2 taking on a leadership position at an upcoming competition, something that she may not have otherwise done: "[Lead 2] had suggested that would be a good leadership opportunity for me so I'm doing that. So, I think that wouldn't have happened if I wasn't in the program" (CD 2). For CD 1, she has applied her learning from the WiSL to her coaching, education, and CD practice. She now focuses on guiding learning, rather than just providing the learners with the answers:

Being a $[\mathrm{CD}]$ the biggest thing that I've taken away from that learning so far is guiding, guiding people to some point. So, I'm the one not giving answers but asking questions to get them to where I would like them to be or where they would like to be. Because it's not always what I want and so I think even just like in my personal life having conversations with friends or that kind of stuff too is just giving me a different perspective. But I think the biggest impact has really been in my [education] career and just connecting the lengths from coaching to [education] and bringing both, both of those things into everything I do. (CD 1)

\section{Additional Considerations}

Although the WiSL is in its first iteration, we draw two additional considerations from this initiative and recommend them to organizations creating and supporting a similar WOTP in sport. It is important to reiterate that this practice paper does not capture the experiences of all $10 \mathrm{CDs}$ in the program but reflects the perspectives of four individuals with different backgrounds and positions informing our practical recommendations.

Including a Male Ally May Create Specific Challenges. The male ally in this project, Lead 2, explained that it was challenging at times to help some of the CDs as they continued to voice their distrust and poor experiences with men in sport: "We're getting a chance to hear different sorts of takes and stories . . . if negative stories are going to be shared, somehow a man was involved." Although Lead 2 wanted to support the CDs in achieving success, years of systematic discrimination made it difficult for the women to disregard their previous experiences. He suggested that it is not only men who perpetuate the double standards in leadership, but it is other women who also create these barriers by not letting women make mistakes and stumble on their journeys to leadership development:
I was horrific in my first five years, it was awful. And so, I stumbled my way to success because it's part of the learning process. So, I just don't think women are given . . . enough leeway to stumble their way to success early on by men and women. (Lead 2)

Burton (2019) explained that "sport operates within a wider context of societal norms and practices" (p. 259), highlighting these persistent examples of gender inequality in leadership that extend far beyond the sport landscape. Thus, it is essential that champions like Lead 2 and Lead 1 continue to push against the many levels of resistance because changes are beginning to occur. For example, the larger AWiSL program is funded by a sector of the Canadian Federal Government, Women and Gender Equality (WAGE). This financial investment and national recognition demonstrated a commitment to change and progress at a cultural level toward empowering women in sport.

Consistent Buy-in From the Organization is Needed. Lead 1 experienced some challenges with her sport organization in terms of prioritizing the $\mathrm{CD}$ program at times. However, she was able to create buy-in through her promotion for the program, and the support and sponsorship from Lead 2. She explained that despite her discomfort with assertiveness, she was going to advocate for the program. She decided:

I'm going to start saying a little bit more like 'this is what we're doing, if you have anything more to add but we're going to proceed with some of this stuff'.... That's out of my comfort zone, doing some things like that especially when I don't know people. (Lead 1)

Through Lead 1's perseverance to move beyond her comfort zone, she was able to secure the necessary funds to move the CDs forward with their learning. Lead 1 also truly believed in the power of this program to increase gender equity and improve women's leadership capacity. Her deeply held beliefs fueled progress despite waning organizational support at times. Lead 1 reflected:

Even, you know from the sort of top down, everybody is getting better and stronger in their roles because of this program. I think it would be, I'm trying to think of . . . a negative; you know and I really can't, I can't think of a negative. I think everybody's benefiting which is really neat. (Lead 1$)$

\section{Conclusion}

According to Cunningham and Ahan (2019) there is "ample evidence of access discrimination in sport" (p. 87). The practical examples highlighted in this paper serve the dual purpose of sharing examples of how one sport organization is taking active measures to change gender inequity and support women's leadership in the organization. More specifically, through developing a women-only cohort of CDs, the organization of focus has begun the slow process of changing the sport leadership landscape. We wish to draw specific attention to the strengths and potential implications of bringing a group of women together and enabling them to engage in leadership development through social learning opportunities. Support at the micro, meso, and macro levels of sport and the context women work in, is essential. Sport organizations striving to shift toward gender equity and increase the number of women in leadership roles should carefully plan for ways to influence all three levels of their organization and the system. Social learning spaces are valuable when designed, organized, and 
facilitated in ways that are meaningful and engaging for the specific women participating. More specifically, a champion (Lead 1) with a firm belief and conviction in the value of the network of women, one who will ensure inclusive ways to connect over time and great distance, is essential for success. Allies make a difference, and, in this case, the sponsorship role of the male ally played by Lead $2 \mathrm{had}$ an essential impact on this program's early success. We recommend this style of women in sport program because it can benefit women with different biographies and women living across rural and urban areas. Sport organizations should consider translating promising practices and lessons learned to their unique contexts and facilitating similar programs to promote gender equity and leadership development for women in sport.

\section{References}

Aicher, T.J., \& Sagas, M. (2009). An examination of homologous reproduction and the effects of sexism. Journal for the Study of Sports and Athletes in Education, 3(3), 375-386. doi:10.1179/ssa.2009.3.3.375

Allen, J.B., \& Reid, C. (2019). Scaffolding women coaches' development: A program to build coaches' competence and confidence. Women in Sport and Physical Activity Journal, 27(2), 101-109. doi:10.1123/ wspaj.2018-0047

Auster, E.R., \& Prasad, A. (2016). Why do women still not make it to the top? Dominant organizational ideologies and biases by promotion committees limit opportunities to destination positions. Sex Roles, 75(5), 177-196. doi:10.1007/s11199-016-0607-0

Belding, M., \& Dodge, A. (2016). Examining the benefits of female-tofemale mentorship as a result of participation in a female coach mentorship program. Canadian Journal for Women in Coaching, $16(2), 1-5$.

Bertram, R., Culver, D.M., \& Gilbert, W. (2017). A university sport coach community of practice: Using a value creation framework to explore learning and social interactions. International Journal of Sports Science \& Coaching, 12(3), 287-302. doi:10.1177/ 1747954117710503

Bronfenbrenner, U. (1977). Toward an experimental ecology of human development. American Psychologist, 32(7), 513-531. doi:10.1037/ 0003-066X.32.7.513

Bronfenbrenner, U. (1979). The ecology of human development: Experiments by nature and design. Cambridge, MA: Harvard University Press.

Bullough, A., De Luque, M.S., Abdelzaher, D., \& Heim, W. (2015). Developing women leaders through entrepreneurship education and training. Academy of Management Perspectives, 29(2), 250-270. doi:10.5465/amp.2012.0169

Burton, L.J. (2015). Underrepresentation of women in sport leadership: A review of research. Sport Management Review, 18(2), 155-165. doi:10.1016/j.smr.2014.02.004

Burton, L.J. (2019). Under-representation of women in leadership roles in women's sport. In N. Lough \& A. Geurin, (Eds.). Routledge handbook of the business of women's sport (pp. 255-268). London, UK: Routledge.

CAAWS. (2018). Women in sport leadership: Board snapshot 2017-2018. Retrieved from https://www.canadianwomen.org/our-work/genderequality-network-canada/

Carson, F., McCormack, C., \& Walsh, J. (2018). Women in sport coaching: Challenges, stress and wellbeing. Journal of Physical Education, Sport, Health and Recreations, 7(1), 63-67. Retrieved from http:// journal.unnes.ac.id/sju/index.php/peshr

Chuang, S. (2019). Exploring women-only training program for gender equality and women's continuous professional development in the workplace. Higher Education, Skills and Work-Based Learning, 9(3), 359-373. doi:10.1108/HESWBL-01-2018-0001

Cragg, S., Costas-Bradstreet, C., Arkell, J., \& Lofstrom, K. (2016). Policy and program considerations for increasing sport participation among members of under-represented groups in Canada: A literature review. Ottawa, ON: Interprovincial Sport and Recreation Council.

Creswell, J. (2013). Qualitative inquiry \& research design: Choosing among five approaches (3rd ed.). Thousand Oaks, CA: Sage.

Culver, D.M., Kraft, E., Din, C., \& Cayer, I. (2019). The Alberta women in sport leadership program: A social learning intervention for gender equity and leadership development. Women in Sport and Physical Activity Journal, 27(2), 110-117. doi:10.1123/wspaj.2018-0059

Cunningham, G.B., \& Ahn, N.Y. (2019). The role of bias in underrepresentation of women in leadership positions. In N. Lough \& A. Geurin (Eds.), Routledge handbook of the business of women's sport (pp. 83-94). London, UK: Routledge.

Demers, G., Thibault, L., Brière, S., \& Culver, D.M. (2019). Women in leadership positions within Canadian sport. In N. Lough \& A. Geurin, (Eds.), Routledge handbook of the business of women's sport (pp. 106-123). London, UK: Routledge.

Gronowski, A.M., \& Burnham, C.D. (2018). Creation of a professional development program for women in a major US medical school pathology department. The Journal of Applied Laboratory Medicine, 3(3), 498-506. doi:10.1373/jalm.2018.026823

Kalaitzi, S., Czabanowska, K., Fowler-Davis, S., \& Brand, H. (2017). Women leadership barriers in healthcare, academia and business. Equality, Diversity and Inclusion: An International Journal, 36(5), 457-474. doi:10.1108/EDI-03-2017-0058

Kane, M.J. (2016). A socio-cultural examination of a lack of women coaches in sport leadership. In N.M. LaVoi (Eds.), Women in sports coaching (pp. 35-48). London, UK: Routledge

Knoppers, A. (1992). Explaining male dominance and sex segregation in coaching: Three approaches. Quest, 44(2), 210-227. doi:10.1080/ 00336297.1992 .10484051

LaVoi, N.M. (2016). A framework to understand experiences of women coaches around the globe. In N.M. LaVoi (Eds.), Women in sports coaching (pp. 13-34). London, UK: Routledge.

LaVoi, N.M., \& Dutove, J.K. (2012). Barriers and supports for female coaches: An ecological model. Sports Coaching Review, 1(1), 17-37. doi:10.1080/21640629.2012.695891

Lumpkin, A., Favor, J., \& McPherson, L. (2013). Who is coaching high school girls' sport teams? Journal of Coaching Education, 6(2), 27-64. doi:10.1123/jce.6.2.27

Machida-Kosuaga, M., Schaubroek, J.M., Gould, D., Ewing, M., \& Feltz, D.L. (2017). What influences collegiate coaches' intentions to advance their leadership careers? The roles of leader self-efficacy and outcome expectancies. International Sport Coaching Journal, 4(3), 265-278. doi:10.1123/iscj.2016-0120

McGinnis, L., Chun, S., \& McQuillian, J. (2003). A review of gendered consumption in sport and leisure. Academy of Marketing Science Review, 5, 1-24. Retrieved from www.vancouver.wsu.edu/otcgi/llscgi60

Melrose, S. (2009). Naturalistic generalization. In A. Mills, G. Durepos, \& E. Weibe (Eds.), Encyclopedia of case study research (pp. 599-601). Thousand Oaks, CA: Sage.

Newland, B.L. (2019). The delivery and management of women-only sports events and their future sustainability. In N. Lough \& A. Geurin (Eds.), Routledge handbook of the business of women's sport (pp. 95-105). London, UK: Routledge.

Shaw, S., \& Hoeber, L. (2003). "A strong man is direct and a direct women is a bitch": Gendered discourses and their influence on employment roles in sport organizations. Journal of Sport Management, 17(4), 347-375. doi:10.1123/jsm.17.4.347 
Walker, N.A., \& Sartore-Baldwin, M. (2013). Hegemonic masculinity and the institutionalized bias toward women as men's basketball coaches: What do men think? Journal of Sport Management, 27(4), 303-315. doi:10.1123/jsm.27.4.303

Walker, N.A., Schaeperkoetter, C., \& Darvin, L. (2017). Institutionalized practices in sport leadership. In L.J. Burton \& S. Leberman (Eds.), Women in sport leadership: Research and practice for change (pp. 33-46). London, UK: Routledge.

Wells, J.E., \& Hancock, M.G. (2017). Networking, mentoring, sponsoring: Strategies to support women in sport leadership. In L.J. Burton \& S.
Leberman (Eds.), Women in sport leadership: Research and practice for change (pp. 130-147). Rotterdam, the Netherlands: Routledge.

Wenger, E. (2011). Social learning capability: Four essays on innovation and learning in social systems. In A. Boddington \& J. Boysn (Eds.), Re-shaping learning: A critical reader (pp. 193-210). Rotterdam, the Netherlands: Sense Publishers.

Wenger, E., Trayner, B., \& de Laat, M. (2011). Promoting and assessing value creation in communities of practice and networks: A conceptual framework (Report 18). Heerlen, the Netherlands: Ruud de Moor Centrum, Open University of the Netherlands. 